\title{
Reproductive and Lifestyle Characteristics of Kenyan Women Presenting With Precancerous Cervical Lesions: A Hospital- Based Case-Control Study
}

\author{
Esther Muitta, ${ }^{a}$ Tom Were, ${ }^{b}$ Anthony N Kebirac \\ aDepartment of Medical Laboratory Sciences, School of Medicine, Mount Kenya University, Thika, Kenya; ${ }^{\circ}$ Department of Medical Laboratory Sciences, School of \\ Public Health, Biomedical Science and Technology, Masinde Muliro University of Science and Technology, Kakamega, Kenya; 'Department of Microbiology, School of \\ Pure and Applied Sciences, Kenyatta University, Nairobi, Kenya \\ Correspondence to Esther Muitta (emuitta@yahoo.com)
}

\begin{abstract}
Background: Cervical cancer is a leading cause of cancer in women, accounting for $68 \%$ of cancer-related deaths among women in developing countries. Several reproductive, lifestyle and demographic risk factors are associated with increased risk for cervical cancer. This study examined the association of risk factors with precancerous cervical lesion grade in women attending Nakuru County Referral Hospital.

Methods: This hospital-based, case-control study was conducted among women aged 20 to 70 years from January to December, 2017. A total of 142 women were recruited into the study and stratified based on precancerous cervical lesion grades based on the Bethesda System as: atypical glandular cells or adenocarcinoma in situ (AGC/AIS, n=8), high-grade squamous intraepithelial lesions (HSIL, $n=59$ ), low-grade squamous intraepithelial lesions (LSIL, $n=35)$, and controls $(n=40)$. Structured questionnaires were used to collect information on demographic, reproductive health, and lifestyle characteristics; anthropometric assessments were conducted. Endocervical swabs and scrapings were obtained from the study participants and used for human papillomavirus (HPV)-16/18, and Pap smear screening.

Results: Age differed significantly among the study groups, with age rising with higher grade of precancerous lesion. Higher rates of HPV 16/18 infection was associated with presenting with AGC/AIS ( $n=8,100.0 \%)$, HSIL $(n=47,79.7 \%)$, and $(n=$ $29,82.9 \%)$, compared to controls $(n=4,10.0 \% ; P<.001)$. History of concomitant lower abdominal pain, vaginal bleeding and discharge was associated with higher risk of precancerous lesion in the HSIL group lodds ratio [OR] 8.9; 95\% confidence interval [Cl], 2.6 to 30.6 ) and the LSIL group (OR 5.8; $95 \% \mathrm{Cl}, 1.8$ to 18.8). Bust circumference $<99 \mathrm{~cm}$ was associated with higher risk of having AGC/AIS (OR 17.4; 95\% Cl, 1.1 to 276.0), HSIL (OR 5.9; 95\% Cl, 2.0 to 17.1), and LSIL (OR 2.7; 95\% $\mathrm{Cl}, 0.9$ to 7.8$)$. Waist circumference $<86 \mathrm{~cm}$ was associated with higher risk of HSIL (OR, $5.4 ; 95 \% \mathrm{Cl}, 1.9$ to 15.4$)$ and LSIL IOR 2.9; $95 \% \mathrm{Cl}, 0.9$ to 8.2). Having a healthy diet was associated with higher odds of $\mathrm{LSIL}(\mathrm{OR}, 4.2 ; 95 \% \mathrm{Cl}, 1.4$ to 12.9 ), but was not associated with HSIL or AGC/AIS.

Conclusion: This study suggests that high-risk HPV 16/18 infection, chronic lower abdominal pain with vaginal bleeding, and decreased upper and lower trunk body mass, are associated with higher risk of precancerous cervical lesions. Integrating targeted cervical cancer screening in routine reproductive health-care services may reduce the risk of developing cervical cancer.
\end{abstract}

\section{INTRODUCTION}

$\mathrm{G}$ lobally, cervical cancer is the fourth most common cancer in women, with an estimated 570,000 new cases and 311,000 deaths in 2018. The burden of cervical cancer is particularly high in sub-Saharan Africa, where it ranks among the top 2 most commonly diagnosed cancers in women, and is a leading cause of cancer-related deaths..$^{1-3}$ In Kenya, over 2000 cervical cancer cases are diagnosed per 100,000 women annually, resulting in an estimated 8,600 deaths in the country each year.4-10
Cervical intraepithelial lesions are the precancerous condition of the cervix, which if left untreated, can develop to cervical cancer. These lesions are characterised by abnormal cellular morphology and are detectable by microscopic examination of cervical epithelial cells obtained through Pap smears. The Bethesda System (TBS) is used to grade the severity of abnormal cell morphology. The most common manifestation of precancerous cervical lesions are low-grade squamous intraepithelial lesion (LSIL) and high-grade squamous intraepithelial 
lesion (HSIL) both of which both are treatable by cervical ablation, cryotherapy or loop electro-excision procedure (LEEP). ${ }^{1-16}$ If left untreated, lesions may progress, and infiltrate adjacent tissue, at which point the disease is diagnosed as an invasive squamous cell carcinoma or, more rarely, a glandular cell cervical cancer (adenocarcinoma). ${ }^{12}$ At this stage, management of lesions is more difficult, and a total abdominal hysterectomy may be recommended in tandem with radiotherapy and/or chemotherapy treatments if metastasis has occurred. ${ }^{17}$

A number of reproductive, lifestyle and demographic risk factors are associated with increased risk for development of cervical cancer. HIV-induced immunodeficiency predisposes women to develop precancerous cervical lesions by enhancing gene expression of oncogenic human papillomavirus (HPV) strains such as high-risk (HR) HPV I6/18, ${ }^{5}$ with immunosuppression increasing risk of progression to cancer..$^{6-9}$ Like HIV, HPV is sexually transmitted, and risk of cervical cancer is associated with sexual risk factors including multiplicity of sexual partners, early sexual debut, high parity and long-term use of hormonal birth control. ${ }^{5-10}$ Demographic factors that have been associated with increased risk of cervical cancer include alcohol and tobacco use, low education, and low socioeconomic status. ${ }^{7,9}$ Malnutrition and wasting may also contribute to increased risk of precancerous cervical lesions in individuals with HPV. ${ }^{13,14}$

To address the high burden of cervical cancer in the country, in June 2019, the Kenyan government implemented mass HPV vaccination, as recommended by many studies, including a 2019 study conducted in Nakuru County, Kenya. ${ }^{10}$ However, many Kenyan women are already infected with HPV, and remain at risk for development of cervical cancer. In the absence of routine screening for cervical intraepithelial lesions though Pap smear, these women may have precancerous cervical lesions that could progress over time. ${ }^{18,19}$ To identify subsets of women at greatest risk of cervical cancer, this study examined the association of reproductive health and lifestyle practices with precancerous cervical lesion grades in women attending Nakuru County Referral Hospital (NCRH).

\section{METHODS}

\section{Study Site}

The study was conducted at the Reproductive Health Services Department of the Maternal and Child Health (MCH) Unit at NRCH, a 250-bed capacity referral hospital in Nakuru County, Kenya serving a population of about 1.2 million residing in the city of Nakuru, its suburbs and rural environs. ${ }^{20}$ The MCH Unit provides medical services for maternal health, including reproductive health, birth control and pre and post natal services. Monthly outpatient attendance at the $\mathrm{MCH}$ unit ranges from 150 to 200 women.

\section{Study Design and Selection of Study Participants}

This hospital-based, case-control study assessed the relationship of reproductive and lifestyle factors with precancerous cervical lesion grades in women attending outpatient reproductive health services at the $\mathrm{MCH}$ Unit of $\mathrm{NRCH}$ from January to December of 2017. Four groups of women were recruited into the study, based on findings from cervical visual inspection with acetic acid and lugol's iodine (VIA/VILI test). The groups were: (1) women with atypical glandular cells or adenocarcinoma in situ (AGC/AIS, $n=8$ ), (2) women with high squamous intraepithelial lesions (HSIL, $\mathrm{n}=59$ ), (3) women with low squamous intraepithelial lesions (LSIL, $\mathrm{n}=35$ ), and (4) control women in whom no abnormal cellular morphology was observed. Health-seeking women were recruited from the $\mathrm{MCH}$ on clinic visit days where suitability to participate was first ascertained through an informed consent process. Enrolment of study subjects was purposively done through the enforcement of predetermined inclusion criteria, which successfully admitted 208 study participants. Data from 142 out of 208 study participants were considered. Sixty-six enrollees' data were invalidated and disregarded during data cleaning, for a variety of reasons, which included invalid questionnaire response entries and entries made from participants with unsuitable human specimens for laboratory analysis. All women seeking reproductive health services from the $\mathrm{MCH}$ on clinic visit days where screened for eligibility and exclusion criteria. All study participants were above the age of 20 years and had pretested positive using cervical visual inspection with acetic acid and Lugol's iodine (VIA/VILI). Pregnant women, in addition to those who were unwilling to participate or did not meet the inclusion criteria, were excluded. VIA/VILI-positive women were purposively targeted, as it was believed that their diagnosis at this stage was an indication that sexual debut had occurred.

\section{Sampling Procedure and Sample Size}

An operationalised sample size, calculated from data obtained on cervical cancer burden statistics-which considered figures from Nakuru county as well from the Kenyan cancer registry pilot preliminary records-was estimated using the formulat described by Kothari et al $^{1,2,20,21}$ : $\mathrm{nf}=\mathrm{n} /(1+\mathrm{n} / \mathrm{N})$

We applied this formula assuming pairwise comparisons between controls and each category of precancerous lesions, and that the ratio between controls and cases would be approximately 1 . Our minimum OR of interest was 3.5, and we assumed that explanatory factors would be present in $25 \%$ to $75 \%$ of the control group. Using this formula we obtained a minimum sample size of about 40 per group. The study included a total of 142 participants, including 40 controls, 35 women in the LSIL group, 59 women in the HSIL group and 8 women in the AGC/AIS group. 


\section{Data Collection and Laboratory Investigations}

Data collection procedures were conducted by clinical staff, including nurses, pathologists and cytotechnicians from Nakuru County Referral Hospital; all study staff underwent a structured protocol training prior to study commencement. Information on participant demographics, reproductive health and lifestyle practices, diet and physical exercise were captured in 1-on-1 interviews conducted in the national language of English and translated to Swahili when necessary. with study participants using a structured questionnaire. If a participant did not understand a question, or provided an ambiguous response, the interviewer probed for greater depth or clarity using structured questionnaire probes, which were designed based on validated probes from similarly designed studies. ${ }^{9,22,23}$ Information on diet was obtained through questions regarding weekly food intake using a checklist of food items common in Nakuru County. Study participants were also asked questions regarding the type, frequency and intensity of their physical activity on weekly basis. Questions and categorisations regarding diet and physical activity were developed based on published methodologies of studies collecting similar data. ${ }^{24,25}$ Study participants underwent anthropometric assessment including measurement of body weight, height, mean-upper-arm circumference (MUAC), bust girth and waist circumference. Data on body weight in kilograms and height in meters were used to calculate the body mass index (BMI).

Both cervical swabs and scrape specimens were obtained. Swabs were collected for STI screening (HR HPV 16/18, for example), while scrapes were collected for cellular material in Pap smear preparations that were stained and examined for atypical diversity. Briefly, scrapes were excavated from the cervical wall using a cervical brush; scraped tissue embedded in the brush was smeared onto microscopic glass slides, fixed while wet, stained after drying using Papanicalou staining techniques and dyes (Heamatoxylin, EA 50 and OG 6) and mounted. ${ }^{26}$ Smears were microscopically examined for the presence of abnormal cellular morphology and graded using TBS. ${ }^{18,27}$ Study participants were categorised into 4 discrete cytology categories based on their TBS score as: control (no cytological abnormality), LSIL, HSIL and AGC/AIS. All smears positive for cervical cancer (AGC/AIS) were confirmed by an independent clinical cytologist. All cervical specimens underwent assessment for HR HPV 16/18 using a commercial kit (StrongStep ${ }^{\circledR}$ HPV 16/18 Antigen Rapid Test Device,Limingo Bio), that detects viral antigens. ${ }^{28}$

\section{Data Analysis}

Study questionnaires were data entered into into Microsoft Office Excel (Microsoft Corp., Redmond, WA, USA) and then exported into IBM SPSS Statistics for Windows version 21.0 (IBM Corp, Armonk, NY, USA), where data were checked for presence of outliers and data errors. Bivariate analyses were conducted to assess associations between reproductive health and lifestyle factors and cervical cytology category. In bivariate analyses, Kruskal-Wallis and analysis of variance (ANOVA) tests were used to test for differences in continuous variables across cytology category; chi-square and Fisher's exact tests were used to test for differences across categorical variables. Multivariate logistic regression modeling analyses were performed to identify reproductive health indicators of precervical cancer grade outcome for HR HPV 16/18, clinical history of lower abdominal pain and vaginal bleeding, parity, and multiplicity of sexual partners. Precervical cancer grade outcomes of LSIL, HSIL, and AGC/AIS were entered as the dependent variables; predictors were HR HPV 16/18-positive outcomes, the manifestations of a clinical history of lower abdominal pain and vaginal bleeding, having more than 2 children, and having more than 1 sexual partner with references of the nonclinical manifestations of pain and bleeding history, having less than 2 children, and having less than 1 sexual partner, respectively. The confounding effects of age, birth control method, cervical cancer disease awareness, marital status, and education level were controlled for in the regression model. Data are presented as ORs and $95 \%$ CIs. The $\beta$ coefficient indicates the degree of association differences for the model.

All independent variables that associated significantly by use of the Kruskal-Wallis test $(P \leq .01)$ with the dependent variable (precervical cancer status indicated by LSIL, HSIL, or AGC/AIS precancer grades) were further additionally analysed using Dunn's post hoc correction for between-group comparisons (multiple comparisons) to assess which specific precancer group significantly differed by ANOVA (Kruskal-Wallis test) (Table 5).

\section{Ethical Considerations}

Written informed consent was conducted in all study participants prior to carrying out any study procedures. Regardless of their willingness to consent, women with abnormal cytology results were counseled and advised to seek further clinical management from the health-care providers in the MHC clinic. Referral to specialists for symptomatic participants was advised for further management. Ethical approvals were obtained from Kenyatta University Ethical Research Committee (KUERC-KU/R/COMM/51/228; PKU/141/I124) and the Kenya National Council of Science Technology and Innovation (NACOSTI-NACOSTI/RCD/12A/013/148). Institutional approval was provided by the Nakuru County Referral Hospital (RII/VOL.I/08). Special coding for participant data was applied to maintain participant anonymity.

\section{RESULTS}

In total, 142 women were enrolled in the study. Most women were married, had not completed secondary education, and were employed in the informal sector (Table 1). Several demographic variables were associated with detection of abnormal cytology in bivariate analysis. Women presenting 
TABLE 1. Characteristics of the Study Participants ( $N=142)$

\begin{tabular}{|c|c|c|c|c|c|c|}
\hline Characteristic & $\begin{array}{c}\text { Controls, } n=40 \\
n(\%)\end{array}$ & $\begin{array}{c}\text { LSIL, } n=35 \\
n(\%)\end{array}$ & $\begin{array}{c}\text { HSIL, } n=59 \\
n(\%)\end{array}$ & $\begin{array}{c}{\text { AGC } / \text { AIS }^{\mathrm{a}},}, \mathrm{n}=\mathbf{8} \\
\mathrm{n}(\%)\end{array}$ & $\begin{array}{c}X^{2}, \text { Degrees of } \\
\text { Freedom }\end{array}$ & P Value $^{b}$ \\
\hline $\begin{array}{l}\text { Median age, } \\
\text { years (range) }\end{array}$ & $34(21-55)$ & $38(20-57)$ & $42(27-63)$ & $65(50-70)$ & & $<.001$ \\
\hline \multicolumn{7}{|l|}{ Education } \\
\hline$\leq$ Primary & $21(52.5)$ & $17(48.6)$ & $43(72.9)$ & $5(62.5)$ & \multirow{2}{*}{$10.226,3$} & \multirow{2}{*}{.017} \\
\hline$>$ Secondary & $19(47.5)$ & $18(51.4)$ & $16(27.1)$ & $3(37.5)$ & & \\
\hline \multicolumn{7}{|l|}{ Occupationc } \\
\hline $\begin{array}{l}\text { Informal } \\
\text { sector }\end{array}$ & $21(52.5)$ & $15(42.9)$ & $33(55.9)$ & $6(75)$ & \multirow{3}{*}{$2.408,6$} & \multirow{3}{*}{.879} \\
\hline $\begin{array}{l}\text { Small } \\
\text { businesses }\end{array}$ & $15(37.5)$ & $15(42.9)$ & $19(32.2)$ & $2(25)$ & & \\
\hline $\begin{array}{l}\text { Formal } \\
\text { employment }\end{array}$ & $4(10)$ & $5(14.3)$ & $7(11.9)$ & $0(0)$ & & \\
\hline \multicolumn{7}{|l|}{ Marital status } \\
\hline Married & $30(75)$ & $21(60)$ & $35(59.3)$ & $3(37.5)$ & \multirow{2}{*}{$2.940,3$} & \multirow{2}{*}{.401} \\
\hline Single & $10(25)$ & $14(40)$ & $24(40.7)$ & $5(62.5)$ & & \\
\hline \multicolumn{7}{|l|}{ HR HPV16/18 } \\
\hline Yes & $4(10)$ & 29 (82.9) & 47 (79.7) & $8(100)$ & \multirow{2}{*}{$62.681,3$} & \multirow{2}{*}{$<.001$} \\
\hline No & $36(90)$ & $6(17.1)$ & $12(20.3)$ & $0(0)$ & & \\
\hline
\end{tabular}

History of simultaneous lower abdominal pain, vaginal bleeding, and vaginal discharge

$\begin{array}{ccccccc}\text { Yes } & 30(75) & 33(94.3) & 56(94.9) & 8(100) & 11.926,3 & .008 \\ \text { No } & 10(25) & 2(5.7) & 3(5.1) & 0(0) & \end{array}$

History of lower abdominal pain and vaginal bleeding only

$\begin{array}{lcccccc}\text { Yes } & 20(50) & 30(85.7) & 54(91.5) & 8(100) & 27.553,3 & <.001 \\ \text { No } & 20(50) & 5(14.3) & 5(8.5) & 0(0) & \end{array}$

History of lower abdominal pain and vaginal discharge only

$\begin{array}{lllllll}\text { Yes } & 25(62.5) & 25(71.4) & 41(69.5) & 6(75) & & \\ \text { No } & 15(37.5) & 10(28.6) & 18(30.5) & 2(25) & 0.938,3 & .816\end{array}$

Birth control use

\begin{tabular}{|c|c|c|c|c|c|}
\hline Hormonal & $18(45)$ & $18(51.4)$ & $33(56)$ & $0(0)$ & \\
\hline $\begin{array}{l}\text { Non- } \\
\text { hormonal }\end{array}$ & $16(40)$ & $10(28.6)$ & 14 (23.7) & $0(0)$ & $21.993,6$ \\
\hline None & $6(15)$ & $7(20)$ & $12(20.3)$ & $8(100)$ & \\
\hline
\end{tabular}


TABLE 1. Continued

\begin{tabular}{|c|c|c|c|c|c|c|}
\hline Characteristic & $\begin{array}{c}\text { Controls, } n=40 \\
n(\%)\end{array}$ & $\begin{array}{c}\text { LSIL, } n=35 \\
n(\%)\end{array}$ & $\begin{array}{c}\text { HSIL, } n=59 \\
n(\%)\end{array}$ & $\begin{array}{c}\text { AGC/AIS }{ }^{\mathrm{a}}, \mathrm{n}=\mathbf{8} \\
\mathrm{n}(\%)\end{array}$ & $\begin{array}{c}X^{2}, \text { Degrees of } \\
\text { Freedom }\end{array}$ & $P$ Value ${ }^{b}$ \\
\hline \multicolumn{7}{|l|}{ Parity } \\
\hline$\geq 2$ & $22(55)$ & $19(54.3)$ & $37(62.7)$ & $7(87.5)$ & \multirow{2}{*}{$1.834,3$} & \multirow{2}{*}{.001} \\
\hline$<2$ & $18(45)$ & $16(45.7)$ & $22(37.3)$ & $1(12.5)$ & & \\
\hline \multicolumn{7}{|c|}{ Number of sexual partners } \\
\hline$>1$ & $10(25)$ & $13(37.1)$ & $30(50.8)$ & $2(25)$ & \multirow{2}{*}{$6.776,3$} & \multirow{2}{*}{.079} \\
\hline$\leq 1$ & $30(75)$ & $22(62.9)$ & $29(49.2)$ & $6(75)$ & & \\
\hline \multicolumn{7}{|c|}{ Knowledge of cervical cancer cause } \\
\hline Don't know & $20(50)$ & $24(68.6)$ & $32(54.0)$ & $2(25)$ & \multirow{4}{*}{$25.843,9$} & \multirow{4}{*}{.002} \\
\hline Infections & $7(17.5)$ & $4(11.4)$ & $7(11.9)$ & $0(0)$ & & \\
\hline Poor hygiene & $4(10)$ & $7(20)$ & $18(30.5)$ & $6(75)$ & & \\
\hline Witchcraft & $9(22.5)$ & $0(0)$ & $2(3.4)$ & $0(0)$ & & \\
\hline
\end{tabular}

Data are presented as frequency, $\mathrm{n}$ (percentage, \%), unless otherwise indicated; a Merged group including participants presenting with both precervical cancer grade AGC and AGC/AIS, since only 1 participant was found to have precancer of AIS. 'bifferences in age across the study groups were compared using the Kruskal-Wallis test. Comparisons in categorical variables were performed using the Pearson's chi-square test for proportions or Fisher's exact test; 'All participants who identified themselves as housewives (unemployed) concurrently responded that they were involved in small-scale enterprise.

Abbreviations: AGC, atypical glandular cells; AIS, adenocarcinoma in situ; HSIL, high-grade squamous intraepithelial lesion; LSIL, low-grade squamous

intraepithelial lesion

with AGC/AIS had a significantly higher median age in years (65; range, 50 to 70 years) years compared to women with HSIL (42; range, 27 to 63 years)), LSIL (38; range, 20 to 57 years years), and controls (34; range, 21 to 55 years; $P<.001$ ) (Table 1). The proportion of the women with less than a secondary education was higher in the AGC/AIS $(n=5,62.5 \%)$ and HSIL groups ( $\mathrm{n}=43,72.9 \%)$ compared to the LSIL $(\mathrm{n}=17$, $48.6 \%)$ and control groups $(n=21,52.5 \% ; P=.079)$. The distribution of occupational types and marital status were similar across cervical cytology groups.

In bivariate analysis, several reproductive risk factors were more frequent in women with abnormal cervical cytology compared to controls, with frequency increasing with higher category of abnormality. History of simultaneous lower abdominal pain, vaginal bleeding, and discharge was significantly more prevalent in the AGC/AIS $(n=8,100.0 \%)$, HSIL $(n=56,94.9 \%)$, and LSIL $(n=33,94.3 \%)$ compared with controls $(\mathrm{n}=30,75.0 \%$; $P=.008)$. Similarly, history of lower abdominal pain with vaginal bleeding was significantly more prevalent in the AGC/AIS $(n=8,100.0 \%)$, HSIL $(n=54$, $91.5 \%)$, and LSIL groups $(n=30,85.7 \%)$ compared to controls $(\mathrm{n}=20,50.0 \% ; P<.001)$. All women in the AGC/AIS group $(n=8,100.0 \%)$ reported not using any birth control methods, compared to a minority of women in the HSIL group $(n=12$,
$20.3 \%)$, the LSIL group $(\mathrm{n}=7,20.0 \%)$ and the control control $(\mathrm{n}=6,15.0 \% ; P=.001)$. Parity $\geq 2$ was higher among women in the AGC/AIS $(n=7,87.5 \%)$ and HSIL $(n=37,62.7 \%)$ groups compared to the LSIL $(n=19,54.3 \%)$ and control groups $(\mathrm{n}=22,55.0 \% ; P=.001)$. Frequency of multiple sexual partners varied across cervical cytology group, though differences did not achieve statistical significance. Having multiple sexual partners was most common among women in the HSIL $(n=30,50.8 \%)$ and LSIL groups $(n=13,37.1 \%)$, compared to women in the AGC/AIS $(n=2,25 \%)$ and control groups $(\mathrm{n}=10,25.0 \% ; P=.079)$. Prevalence of HR HPV 16/18 was over $80 \%$ among women with abnormal cervical cytology, with the highest prevalence in the AGC/AIS group $(n=8,100.0 \%)$ compared to the HSIL group $(n=47,79.7 \%)$, the LSIL group $(n=29,82.9 \%)$ and the control group $(n=4,10.0 \% ; P<.001)$.

In bivariate analysis of anthropometric measurements, diet and activity revealed a number of differences across the cervical cytology groups. Median weight in kilograms was higher in the AGC/AIS group (73.0; range, 52.0 to 86.0 kilograms), compared to HSIL (70.0; range, 44.0 to $96.0 \mathrm{ki}$ lograms), LSIL (70.0; range, 45.0 to 70.0 kilograms) and controls groups (71.0; range, 45.0 to 89.0 kilograms; $P=.036$ ) (Table 3$)$. Median bust girth in centimeters $(\mathrm{cm})$ was lower in the AGC/AIS (median, 96.0; range, 76.0 to $101.0 \mathrm{~cm}$ ), HSIL 
TABLE 2. Multivariate Logistic Regression Analysis of Reproductive Risk Factors and Cervical Lesion Groups

\begin{tabular}{lccccc}
\hline & Characteristic & $\boldsymbol{\beta}$ & OR & $\mathbf{9 5 \%} \mathbf{C l}$ & $\boldsymbol{P}$ Value \\
\hline HR HPV 16/18 & & & & \\
LSIL & 3.913 & 50.055 & $11.993-208.913$ & $<.001$ \\
HSIL & 3.592 & 36.323 & $9.456-139.525$ & $<.001$ \\
AGC/AIS & 21.390 & 1.947 & $1.940-1.947$ & $<.001$
\end{tabular}

History of simultaneous lower abdominal pain, vaginal bleeding and discharge

LSIL

HSIL

1.758

5.800

1.795-18.739

.003

AGC/AIS

2.183

8.873

2.576-30.561

.001

Parity $\geq 2$

LSIL

25.347

1.019

$1.000-1.019$

$<.001$

HSIL

$-0.216$

0.806

$0.270-2.408$

.699

AGC/AIS

$-0.654$

0.520

$0.178-1.515$

.231

0.465

1.592

$0.034-74.450$

.813

\section{Multiple sex partners $>1$}

LSIL

0.125

1.134

0.256-5.016

.755

HSIL

1.350

3.859

$0.905-16.450$

.068

AGC/AIS

$-0.602$

0.548

0.013-23.896

.216

Multivariate logistic regression model analyses were performed to identify reproductive health indicators of precervical cancer grade outcome for HR HPV $16 / 18$, clinical history of lower abdominal pain and vaginal bleeding, parity, and multiplicity of sexual partners.

Precervical cancer grade outcomes of LSIL, HSIL, and AGC/AIS were entered as the dependent variables; predictors were HR HPV 16/18-positive outcomes, the manifestations of a clinical history of lower abdominal pain and vaginal bleeding, having more than 2 children, and having more than 1 sexual partner with references of the nonclinical manifestations of pain and bleeding history, having less than 2 children, and having less than 1 sexual partner, respectively. The confounding effects of age, birth control method, cervical cancer disease awareness, marital status, and education level were controlled for in the regression model. Data are presented as ORs and 95\% Cls. The $\beta$ coefficient indicates the degree of association differences for the model.

Abbreviations: AGC, atypical glandular cells; AIS, adenocarcinoma in situ; CI, confidence interval; HR HPV, high-risk human papillomavirus; HSIL, high-grade squamous intraepithelial lesion; LSIL, low-grade squamous intraepithelial lesion; OR, odds ratio

(98.0; range, 74.0 to $126.0 \mathrm{~cm}$ ), and LSIL (100.0; range, 70.0 to $122.0 \mathrm{~cm}$ ) groups compared to the control group (73.0; range, 52.0 to $86.0 \mathrm{~cm} ; P=.004)$. Likewise, median waist circumference in centimetres was lower in women with AGC/AIS (74.0; range, 64.0 to $90.0 \mathrm{~cm}$ ), HSIL (83.0; range, 56.0 to $112.0 \mathrm{~cm}$ ), and LSIL (86.0; range, 54.0 to $114.0 \mathrm{~cm}$ ) compared to controls (90.0; range, 51.0 to $109.0 \mathrm{~cm} ; P=.002$ ). Height, BMI and MUAC were similar across the cervical cytology groups. In all cervical cytology groups, $80 \%$ to $90 \%$ of women reported engaging in physical activity. The proportion of women with a healthy diet was was higher in the AGC/AIS $(n=5,62.5 \%)$ and HSIL $(\mathrm{n}=39,66.0 \%)$ groups compared to the LSIL $(\mathrm{n}=11,31.4 \%)$ and control $(\mathrm{n}=13,33.0 \% ; P=.004)$ groups. The proportion of women reporting use of alcohol or tobacco use was low and did not vary significantly across the cervical cytology groups.
In logistic modelling, detection of HR HPV 16/18 was associated with a significantly higher risk of AGC/AIS (odds ratio [OR] $1.947 ; 95 \%$ confidence interval [CI], 1.940 to 1.947$)$, HSIL (OR 36.3; $95 \%$ CI, 9.5 to 139.5), or LSIL (OR 50.1; 95\% CI, 11.9 to 208.9) (Table 2). Likewise, a history of concomitant lower abdominal pain and vaginal bleeding was associated with higher risk of presenting with AGC/AIS (OR 1.0; $95 \%$ CI, 1.0 to $1.0 ; P<.001$ ), HSIL (OR 8.8; $95 \%$ CI, 2.6 to 30.6), and LSIL (OR 5.8; 95\% CI, 1.8 to 18.7). Regression analyses also illustrated that high odds of having AGC/AIS (OR 17.4; 95\% CI, 1.1 to 276.0 ), HSIL (OR 5.9; 95\% CI, 2.0 to 17.1), and LSIL (OR 2.7; $95 \%$ CI, 0.9 to 7.8 ) were associated with a bust circumference $\leq 99 \mathrm{~cm}$ compared to a bust circumference $>99$ $\mathrm{cm}$ (Table 4 ). In addition, waist circumference $\leq 86 \mathrm{~cm}$ was associated with a higher odds of HSIL (OR, 5.4; $95 \%$ CI, 1.9 to 
TABLE 3. Anthropometric, Diet and Physical Activity Characteristics of the Study Participants

\begin{tabular}{|c|c|c|c|c|c|c|}
\hline Characteristic & $\begin{array}{c}\text { Controls, } n=40 \\
n(\%)\end{array}$ & $\begin{array}{c}\text { LSIL, } n=35 \\
n(\%)\end{array}$ & $\begin{array}{c}\text { HSIL, n=59 } \\
n(\%)\end{array}$ & $\begin{array}{c}\text { AGC/AIS, } n=8 \\
n(\%)\end{array}$ & $\begin{array}{l}X^{2}, \text { Degrees } \\
\text { of Freedom }\end{array}$ & $\begin{array}{c}P \text { value } \\
- \\
\end{array}$ \\
\hline Weightb, kg & 71 (45-89) & $70(45-70)$ & $70(44-96)$ & $73(52-86)$ & - & .0348 \\
\hline Heightb, m & $1.6(1.5-1.8)$ & $1.6(1.5-1.8)$ & $1.6(1.5-1.8)$ & $1.6(1.5-1.6)$ & - & .763 \\
\hline $\mathrm{BMI}^{\mathrm{b}}, \mathrm{kg} / \mathrm{m}^{2}$ & $26(19-34.0)$ & $25(20-35)$ & $24(16-33)$ & $27.5(21-33)$ & - & .570 \\
\hline MUAC $^{b}, \mathrm{~cm}$ & $33(23-45)$ & $31(20-44)$ & $30(21-42)$ & $32(23-34)$ & - & .110 \\
\hline Bust $^{b}, \mathrm{~cm}$ & 103 (78-122) & $100(70-122)$ & $98(74-126)$ & $96(76-101)$ & - & .0035 \\
\hline Waist ${ }^{b}, \mathrm{~cm}$ & $90(51-109)$ & $86(54-114)$ & $83(56-112)$ & $74(64-90)$ & - & .0045 \\
\hline \multicolumn{7}{|l|}{ Physical activity } \\
\hline Yes & $22(80.0)$ & 33 (94.3) & $56(94.9)$ & $8(100)$ & \multirow{2}{*}{$7.679,3$} & \multirow{2}{*}{.050} \\
\hline No & $8(20.0)$ & $2(5.7)$ & $3(5.1)$ & $0(0)$ & & \\
\hline \multicolumn{7}{|l|}{ Diet } \\
\hline Healthy & $13(33.0)$ & $11(31.4)$ & $39(66)$ & $5(62.5)$ & \multirow{2}{*}{$13.175,3$} & \multirow{2}{*}{.004} \\
\hline Unhealthy & $27(70.0)$ & $24(68.6)$ & $20(34)$ & $3(37.5)$ & & \\
\hline \multicolumn{7}{|l|}{ Ever used alcohol } \\
\hline Yes & $3(7.5)$ & $3(8.6)$ & $6(10.2)$ & $1(12.5)$ & \multirow{2}{*}{$0.902,3$} & \multirow{2}{*}{.825} \\
\hline No & $37(92.5)$ & $32(91.4)$ & $53(89.8)$ & $7(87.5)$ & & \\
\hline \multicolumn{7}{|l|}{ Ever used tobacco } \\
\hline Yes & $1(2.5)$ & $2(5.7)$ & $6(10.2)$ & $1(12.5)$ & \multirow{2}{*}{$3.440,3$} & \multirow{2}{*}{.328} \\
\hline No & $39(97.5)$ & $33(94.3)$ & $53(89.8)$ & $7(87.5)$ & & \\
\hline \multicolumn{7}{|c|}{$\begin{array}{l}\text { Data presented are presented as frequency, } n \text { (percentage, \%), of subjects, unless otherwise indicated. Across-group comparisons for continuous variables were } \\
\text { performed using the Kruskal-Wallis test. Comparisons in categorical variables amongst the study groups were performed using the chi-square test for proportions. } \\
\text { aMerged group including participants presenting with both precervical cancer grade AGC and AGC/AIS, since only } 1 \text { participant was found to have precancer } \\
\text { of AIS. bData presented as median (range) }\end{array}$} \\
\hline
\end{tabular}

15.4) and LSIL (OR 2.9; 95\% CI, 0.9 to 8.2). Having a healthy diet was associated with higher odds of LSIL (OR, 4.2; 95\% CI, 1.4 to 12.9), but was not associated with HSIL or AGC/AIS.

Dunn's post hoc corrections were performed on significantly different variables from the Kruskall-Wallis ANOVA (age, weight, bust measurement, and waist circumference) (Table 5).

\section{DISCUSSION}

This case-control study, conducted at a large, public hospital in Kenya, examined the influence of demographic, reproductive, and lifestyle factors on risk of precancerous cervical lesions. Older women with a low level of education had the highest prevalence of HR HPV 16/18 and were more likely to have the highest grade lesions. Consistent with the sexual mode of HPV transmission, sexual and reproductive risk factors, including multiplicity of sexual partners, multiparity, and lack of birth control use were positively associated with abnormal cervical cytology. Strikingly, we detected HR HPV $16 / 18$ in the cervical specimens of over $80 \%$ of women with abnormal cervical cytology, highlighting the importance of this viral strain as a cause of precancerous cervical lesions in Kenya.

Our finding that the median age of women was highest in the AGC/AIS group is consistent with other studies conducted in Africa and Europe, ${ }^{6,21,22,29-31}$ and likely reflects the progression of untreated, precancerous cervical lesions over time. While over $90 \%$ of HPV infections clear within 2 
years ${ }^{11,16}$ even without treatment, some infections, particularly those of oncogenic viral sub-types 16 and 18 , may progress to cancer over a period of 10 to 20 years. ${ }^{16}$ Infection with HR HPV 16/18 strains was common among our study participants, which is consistent with the high prevalence of HR HPV - 16/18 (>60\%) in the general population in Kenya, $, 922,23$ and rates of detection of over $70 \%$ among patients at Kenyatta National Hospital diagnosed with high grade cervical lesions or squamous cell carcinomas. ${ }^{32}$ Thus an accumulation of high grade lesions among older women may reflect the natural history of HPV 16/18 infection in a setting in which screening and treatment for precancerous cervical lesions is largely absent.

We found that over $90 \%$ of women with cervical lesions had concurrent lower abdominal pain, vaginal bleeding and vaginal discharge. In logistical analysis these signs and symptoms were associated with high risk for LSIL, HSIL and AGC/AIS grades, with risk increasing across higher category of cytological abnormality. These findings mirror those of a study conducted in Uganda, which found increased incidence of lower abdominal pain discomfort and vaginal bleeding among patients undergoing treatment for high grade precancerous cervical lesions. ${ }^{33-35}$ The combination of abnormal vaginal bleeding and pelvic pain are common early indicators of metastasis of cervical cancer. ${ }^{35,36} \mathrm{Howev}$ er, these signs and symptoms were also reported $75 \%$ of our study controls, reflecting the low specificity of abdominal pain and vaginal bleeding as criteria for suspicion of precancerous cervical lesions. This lack of specificity underlies current recommendations to screen of all women at risk for cervical cancer, regardless of symptoms.

In our patient population, lack of birth control use and multiparity were significantly associated with detection of precancerous cervical lesions, which is consistent with other studies conducted in Nigeria, the USA and the UK. ${ }^{8,37-39}$ Higher parity may increase the occurrence of ovarian hormone imbalances during and/or following pregnancy. ${ }^{40}$ These imbalances may perturb metaplastic processes during cervical wall development and differentiation in which columnar cells are converted to squamous cells within the transformation zone of parabasal layer of the cervical wall. ${ }^{19}$ Cells undergoing metaplasia are more vulnerable to HPV infection, due to numerous mitotic events which may concurrently propagate HPV DNA transcription in infected cells. ${ }^{15}$

Several studies from Africa, and the U.S. have reported increased risk of cervical cancer in association with having multiple sexual partners. ${ }^{22,40,41}$ However, in logistic analysis controlling for demographic factors, we did not find an association between multiplicity of sexual partners and presence of precancerous cervical lesions. Higher transmission of HR HPV 16/18 strains is thought to underlie the association between multiple sexual partners and increased risk of precancerous cervical lesions or cervical cancer. However, in our study the much lower frequency of HR HPV 16/18 infection among control women was not coupled with a low-
TABLE 4. Multivariate Logistic Regression Analysis of Anthropometric Characteristics and Diet Practices

\begin{tabular}{|c|c|c|c|c|}
\hline Characteristic & $\beta$ & $\begin{array}{l}\text { Odds } \\
\text { Ratio }^{\alpha}\end{array}$ & $95 \% \mathrm{Cl}$ & $P$ Value \\
\hline \multicolumn{5}{|c|}{ Body weight (median $\leq 68 \mathrm{~kg}$ ) } \\
\hline LSIL & -0.087 & 0.9 & $0.3-2.5$ & .863 \\
\hline HSIL & 0.808 & 2.2 & $0.8-5.9$ & .103 \\
\hline AGC/AIS & -1.839 & 0.2 & $0.0-5.8$ & .317 \\
\hline \multicolumn{5}{|c|}{ Bust girth (median $\leq 99 \mathrm{~cm}$ ) } \\
\hline LSIL & 0.974 & 2.7 & $0.9-7.8$ & .077 \\
\hline HSIL & 1.767 & 5.9 & $2.0-17.1$ & .001 \\
\hline AGC/AIS & 2.858 & 17.4 & $1.1-276.1$ & .043 \\
\hline \multicolumn{5}{|c|}{ Waist circumference (median $\leq 86 \mathrm{~cm}$ ) } \\
\hline LSIL & 1.052 & 2.9 & $0.9-8.2$ & .051 \\
\hline HSIL & 1.681 & 5.4 & $1.9-15.4$ & .002 \\
\hline AGC/AIS & 1.816 & 6.2 & $0.5-80.2$ & .166 \\
\hline \multicolumn{5}{|l|}{ Unhealthy diet } \\
\hline LSIL & -1.433 & 4.2 & $\begin{array}{l}1.363- \\
12.881\end{array}$ & .012 \\
\hline HSIL & -0.90 & 1.1 & $\begin{array}{c}0.391- \\
3.062\end{array}$ & .864 \\
\hline AGC/AIS & 3.108 & 0.0 & $\begin{array}{c}0.000- \\
4.065\end{array}$ & .177 \\
\hline
\end{tabular}

Multivariate logistic regression analyses were performed to identify anthropometric and diet indicators of precervical cancer grade outcome for body weight, bust girth, waist circumference, and unhealthy diet consumption. Precervical cancer grade outcomes of LSIL, HSIL, and AGC/AIS were entered as the dependent variables, and predictors of weight medians $\leq 68 \mathrm{~kg}$, bust medians $\leq 99 \mathrm{~cm}$ and waist medians $\leq 86 \mathrm{~cm}$, including median values above the stated, as references in the regression model. Unhealthy diet was also entered as a predictor with healthy diet serving as the reference. The confounding effects of age, birth control method choice, cervical cancer disease awareness, marital status, and education level were controlled for in the regression model. Data are presented as OR and $95 \% \mathrm{Cl}$. The $\beta$ coefficient indicates the degree of association differences for model.

Abbreviations: AGC, atypical glandular cells; AIS, adenocarcinoma in situ; $\mathrm{Cl}$, confidence interval; HR HPV, high-risk human papillomavirus; HSIL, high-grade squamous intraepithelial lesion; LSIL, low-grade squamous intraepithelial lesion; OR, odds ratio

er prevalence of having multiple sexual partners. We speculate that the participants in this study group were better informed about safe sexual practices denoted by the high proportion of women who had secondary and above level of education relative to participants who manifested HSIL and AGC/AIS lesions. This result mirrors a study in the US which investigated multiplicity of sexual partners and HR HPV infection. ${ }^{42}$ 
TABLE 5. Dunn's Post Hoc Analysis for Between-Group Analysis of Variance Differences

\begin{tabular}{lcccc}
\hline \multicolumn{1}{c}{ Characteristic } & $\begin{array}{c}\text { Age } \\
\text { (median } \mathbf{3 8} \text { years) }\end{array}$ & $\begin{array}{c}\text { Weight } \\
\text { (median } \leq \mathbf{6 8} \mathbf{~ k g})\end{array}$ & $\begin{array}{c}\text { Bust } \\
\text { (median } \leq \mathbf{9 9} \mathbf{~ c m} \text { ) }\end{array}$ & $\begin{array}{c}\text { Waist } \\
\text { (median } \leq \mathbf{8 6} \mathbf{~ c m} \text { ) }\end{array}$ \\
\hline $\begin{array}{l}\text { Kruskal-Wallis } \\
\text { In between group } \\
\text { median variance }\end{array}$ & $P<.001$ & $P=.0348$ & $P=.0035$ & $P=.0045$ \\
AGC/AIS vs HSIL & $P<.05$ & $P<.05$ & $P<.05$ & $P<.05$ \\
AGC/AIS vs LSIL & $P<.01$ & - & - & - \\
AGC/AIS vs Control & $P<.001$ & - & - & - \\
HSIL vs LSIL & $P<.001$ & - & - & - \\
HSIL vs Control & - & - & $P<.01$ & - \\
LSIL vs Control & $P<.001$ & - & - & -
\end{tabular}

Against our expectation, our analysis revealed that having a healthy diet was more frequent among women in the HSIL and AGC/AIS groups compared to women in the LSIL and control groups. This contrasts with findings from a trial conducted in the U.S. suggesting that high consumption of cruciferous vegetables, which are common in the Kenyan diet, may reduce risk of high grade cervical lesions. In the trial, 12-week oral administration of indole-3-carbinol, a compound found in cruciferous vegetables such as cabbage and kale, was more effective than placebo in regression of precancerous cervical lesions. ${ }^{43}$ Other studies of the association between diet and precancerous cervical lesions are more equivocal. An observational study from India which found no significant difference in 24-hour dietary recall between healthy women and women presenting with LSIL or HSIL. ${ }^{44}$ We speculate that our finding that a healthy diet was more common in women with high grade precancerous lesion may be due to age-related differences in diet, that were not adequately controlled for in analysis.

\section{Limitations}

Our study had several limitations. Due to the retrospective nature of the study, we were unable to evaluate the influence of explanatory factors on progression of precancerous lesions, or report on the frequency of regression. Assessment of diet was based on 1-week recall, and may not have provided a precise estimate of actual food intake. Finally, our sample size was relatively small and may not have allowed for estimation of moderate to small effect sizes.

\section{CONCLUSION}

Protracted clinical histories of lower abdominal pain and heavy vaginal bleeding including recognised reduction of body mass in the upper arms, waist, and bust areas indicat- ing wasting syndrome are important predictors of precervical cancer onset. These signs and symptoms can be applied routinely as valid reasons for conducting a cervical cancer screening when identified in women presenting at the reproductive health clinics, as they may predict precervical cancer development. High median age values suggest that having an advanced age predisposes to precancer predictor signs. Substantial HR HPV $16 / 18$ positivity confirms that this organism is indeed a precursor to precancer development and should be routinely tested or screened for in women seeking reproductive health services.

Acknowledgements: The authors wish to thank all the study participants. We are particularly grateful to the management, medical and laboratory staff of Nakuru County Referral Hospital for providing technical assistance, laboratory space, equipment and Pap smear processing reagents.

This study was supported, in part, by the Mount Kenya University (MEMO-R\&D-001-090). The funding body had no role in designing the study, collection, analysis and interpretation of data.

\section{REFERENCES}

1. World Cancer Research Fund (WCRF). Cervical cancer statistics. WCRF Website. https://www.wcrf.org/dietandcancer/cancer-trends/worldwide-cancer-data.

2. Torre LA, Bray F, Siegel RL, Ferlay J, Lortet-Tieulent J, Jemal A. Global cancer statistics, 2012. CA Cancer J Clin. 2012;65(2):87-108. CrossRef. Medline

3. World Health Organization (WHO). Cervical cancer. WHO Website. https:// www.who.int/cancer/prevention/screening/cervical-cancer/en/.

4. Bray F, Ferlay J, Soerjomataram I, Siegel RL, Torre LA, Jemal A. Global cancer statistics 2018: GLOBOCAN estimates of incidence and mortality worldwide for 36 cancers in 185 countries. CA Cancer J Clin. 2018;68(6):394-424. CrossRef. Medline

5. McCredie M, Sharples K, Paul C, et al. Natural history of cervical neoplasia and risk of invasive cancer in women with cervical intraepithelial neoplasia 3: a retrospective cohort study. Lancet Oncol. 2008;9(5):425-434. CrossRef. Medline

6. Getinet M, Gelaw B, Sisay A, Mahmoud EA, Assefa A. Prevalence and predictors of Pap smear cervical epithelial cell abnormality among HIV-positive and negative women attending gynecological examination in cervical cancer screening center at Debre Markos Referral Hospital, East Goijam, Northwest 
Ethiopia. BMC Clin Pathol. 2015;15:16. CrossRef. Medline

7. Blake $K$, Ottenbacher A, Finney Rutten $\sqcup$, et al. Predictors of human papillomavirus awareness and knowledge in 2013: gaps and opportunities for targeted communication strategies. Am J Prev Med. 2015;48(4):402-410. CrossRef. Medline

8. Auwal IK, Aminu M, Atanda T, Tukur J, Sarkinfada F. Prevalence and high-risk Human Papilloma infections among women attending gynecology clinics in Kano, Northern Nigeria. Bayero J Pure Appl Sci. 2013;6(1). CrossRef

9. Memiah P, Mbuthia W and Kiiru G. Prevalence and risk factors associated with precancerous cervical cancer lesions among HIV-infected women in resource-limited settings. AIDS Res Treat. 2012;2012:953743. CrossRef. Medline

10. Muitta E, Were T, Nyamache AK, Muhoho N. Atypical cervical cytomorphologic predictors: a descriptive study of pre-cervical cancer patients of low education in Kenya. Pan Afr Med J. 2019;33:124. CrossRef. Medline

11. Cancer Research UK. Cervical cancer risks and causes. Cancer Research UK Website. https://www.cancerresearchuk.org/about-cancer/cervical-cancer/ risks-causes.

12. Massad LS, Ahdieh L, Benning L, et al. Evolution of cervical abnormalities among women with HIV-1: evidence from surveillance cytology in the women's interagency HIV study. J Acquir Immune Defic Syndr. 2001 ;27(5):432-442. CrossRef. Medline

13. Fearon KC, Voss AC, Hustead DS; Cancer Cachexia Study Group. Definition of cancer cachexia: effect of weight loss, reduced food intake, and systemic inflammation on functional status and prognosis. Am J Clin Nutr. 2006;83(6):1345-1350. CrossRef. Medline

14. Argilés JM, López-Soriano FJ, Toledo M, Betancourt A, Serpe R, Busquets $S$. The cachexia score (CASCO): a new tool for staging cachectic cancer patients. J Cachexia Sarcopenia Muscle. 2011;2(2):87-93. CrossRef. Medline

15. Burd ME. Human papillomavirus and cervical cancer. Clin Microbiol Rev. 2003;16(1):1-17. CrossRef. Medline

16. American Cancer Society. Cervical cancer. American Cancer Society Website. https://www. cancer.org/cancer/cervical-cancer.html.

17. Vinh-Hung V, Bourgain C, Vlastos $G$, et al. Prognostic value of histopathology and trends in cervical cancer: a SEER population study. BMC Cancer. 2007;7:164. CrossRef. Medline

18. Nayar R, Wilbur DC. The Bethesda System for reporting cervical cytology: a historical perspective. Acta Cytol. 2017;61(4-5):359-372. CrossRef. Medline

19. Ferris DG, Cox JT, O'Connor DM, Wright VC, Foerster J American Society for Colposcopy and Cervical Pathology. Modern Colposcopy Textbook and Atlas. 2nd ed. Dubuque, IW, USA: Kendall/Hunt Publishing Company; 2004.

20. National Coordinating Agency for Population and Development (NCAPD) [Kenya]. Nakuru District Strategic Plan 2005-2010 for Implementation of the National Population Policy for Sustainable Development. Nairobi, Kenya: NCAPD, Ministry of Planning and National Development; 2005.

21. Rajab J, Muchiri L. Cancer registry in two counties: Cancer/HIV linked population-based registries in Embu and Nakuru counties: a pilot project (2010-2016). Kenya Medical Research Institute Website. hitps://www.kemri. org/KASH/ojs-2.4.8-1/index.php/KCAB/article/view/19/0.

22. Were $E$, Nyaberi $Z$, Buziba N. Integrating cervical cancer and genital tract infection screening into mother, child health and family planning clinics in Eldoret, Kenya. Afr Health Sci. 2010;10(1):58-65. Medline

23. Ngugi CW, Boga H, Muigai AW, Wanzala P, Mbithi JN. Factors affecting uptake of cervical cancer early detection measures among women in Thika, Kenya. Health Care Women Int. 2012;33(7):595-613. CrossRef. Medline

24. Shim JS, Oh K, Kim HC. Dietary assessment methods in epidemiologic studies. Epidemiol Health. 2014;36:e2014009. CrossRef. Medline

25. Hills AP, Mokhtar N, Byrne NM. Assessment of physical activity and energy expenditure: an overview of objective measures. Front Nutr. 2014;1:5. CrossRef. Medline

26. Hughes HE, Dodds TC. Handbook of Diagnostic Cytology. 5th ed. Edinburgh, UK: E \& S Livingstone Ltd; 1968.

27. Hirschowitz L, Nucci M, Zaino RJ. Problematic issues in the staging of endometrial, cervical and vulval carcinomas. Histopathology. 2013;62(1):176-202. CrossRef. Medline

26. Liming Bio. HPV 16/18 Antigen rapid test device. Liming Bio Website. http:// www.limingbio.com/uploadfile/2018/0509/20180509035657649.pdf.

29. International Collaboration of Epidemiological Studies of Cervical Cancer,
Appleby $P$, Beral V, et al. Carcinoma of the cervix and tobacco smoking: collaborative reanalysis of individual data on 13,541 women with carcinoma of the cervix and 23,017 women without carcinoma of the cervix from 23 epidemiological studies. Int J Cancer. 2006;1 18(6):1481-1495. CrossRef. Medline

30. International Collaboration of Epidemiological Studies of Cervical Cancer, Appleby P, Beral V, et al. Cervical cancer and hormonal contraceptives: collaborative reanalysis of individual data for 16,573 women with cervical cancer and 35,509 women without cervical cancer from 24 epidemiological studies. Lancet. 2007;370(9599):1609-1621. CrossRef. Medline

31. Domfeh $A$, Wiredu $E$, Adjei $A$, et al. Cervical human papillomavirus infection in Accra, Ghana. Ghana Med J. 2008;42(2):71-78. CrossRef. Medline

32. Karuri JW, Muchiri LW. Conventional Pap smear and human papillomavirus DNA co-testing in HIV infected women attending comprehensive care center in Kenyatta National Hospital [dissertation]. Nairobi, Kenya: University of Nairobi; 2015.

33. Mwaka $A D$, Okello $E S$, Wabinga $H$, Walter FM. Symptomatic presentation with cervical cancer in Uganda: a qualitative study assessing the pathways to diagnosis in a low-income country. BMC Womens Health. 2015;15:15. CrossRef. Medline

34. Krucik GT. Vaginal neoplasms (vaginal tumors and cancer). Healthline Website. https://www.healthline.com/health/vaginal-tumors\#risk-factors.

35. Oriel KA, Schrager S. Abnormal Uterine Bleeding. Am Fam Physician. 1999;60(5):1371-1380. Medline

36. Boardman CH, Matthews KJ, Carter JS, Warner KH. Cervical cancer. Medscape Website. https://emedicine.medscape.com/article/253513-overview.

37. Brisson J, Morin C, Fortier M, et al. Risk factors for cervical intraepithelial neoplasia: differences between low- and high-grade lesions. Am J Epidemiol. 1994;140(8):700-710. CrossRef. Medline

38. Muñoz N, Franceschi S, Bosetti C, et al. Role of parity and human papillomavirus in cervical cancer: the IARC multicentric case-control study. Lancet. 2002;359(9312):1093-1101. CrossRef. Medline

39. Jensen KE, Schmiedel S, Norrild B, Frederiksen K, Iftner T, Kjaer SK. Parity as a cofactor for high-grade cervical disease among women with persistent human papillomavirus infection: a 13-year follow-up. Br J Cancer. 2013;108(1):234239. CrossRef. Medline

40. Williams MA, Kenya PR, Mati JK, Thomas DB. Risk factors for invasive cervical cancer in Kenyan women. Int J Epidemiol. 1994;23(5):906-912. CrossRef. Medline

41. Mwaka AD, Orach CG, Were EM, Lyratzopoulos G, Wabinga $H$, Roland $M$. Awareness of cervical cancer risk factors and symptoms: cross-sectional community survey in post-conflict northern Uganda. Health Expect. 2016;19(4):854-867. CrossRef. Medline

42. Burkett BJ, Peterson CM, Birch LM, et al. The relationship between contraceptives, sexual practices, and cervical human papillomavirus infection among a college population. J Clin Epidemiol. 1992;45(11):1295-1302. CrossRef. Medline

43. Labani L, Andallu B, Meera M, Asthana S, Satyanarayana L. Food consumption pattern in cervical carcinoma patients and controls. Indian J Med Paediatr Oncol. 2009;30(2):71-75. CrossRef. Medline

44. Bell MC, Crowley-Nowick P, Bradlow HL, et al. Placebo-controlled trial of indole-3-carbinol in the treatment of CIN. Gynecol Oncol. 2000;78(2):123-129. CrossRef. Medline

\section{Peer Reviewed}

Competing Interests: None declared.

Received: 4 Oct 2018; Accepted: 21 Oct 2019

Cite this article as: Muitta E, Were T, Kebira AN. Reproductive and Lifestyle Characteristics of Kenyan Women Presenting With Precancerous Cervical Lesions: A Hospital-Based Case-Control Study. East Afr Health Res J. 2019;3(2):115-124. http://doi.org/10.24248/EAHRJ-D-19-00002.

(c) Muitta et al. This is an open-access article distributed under the terms of the $\mathrm{Cre}$ ative Commons Attribution License, which permits unrestricted use, distribution, and reproduction in any medium, provided the original author and source are properly cited. To view a copy of the license, visit http://creativecommons.org/licenses/ by/4.0/. When linking to this article, please use the following permanent link: http:// doi.org/10.24248/EAHRJ-D-19-00002. 